\title{
Recent Progress in Estimating Ship-Hull Drag Penalty
}

\author{
I Ketut Aria Pria Utama ${ }^{1, a, *}$, Bagus Nugroho ${ }^{2, b}$, Jason Monty ${ }^{2, c}$, Nicholas Hutchins ${ }^{2, d}$, and \\ Bharathram Ganapathisubramani ${ }^{3, e}$ \\ ${ }^{1}$ Dept of Naval Architecture, Institut Teknologi Sepuluh Nopember, Surabaya, Indonesia \\ ${ }^{2}$ Dept of Mechanical Engineering, The University of Melbourne, Parkville, Australia \\ ${ }^{3}$ Aerodynamics and Flight Mechanics group, University of Southampton, Southampton, United \\ Kingdom \\ a.kutama@na.its.ac.id,b.bagus.nugroho@unimelb.edu.au,c.montyjp@unimelb.edu.au,d. \\ nhu@unimelb.edu.au,d.G.Bharath@soton.ac.uk \\ *corresponding author
}

\begin{abstract}
Keywords: $\quad$ Shiphull Drag Penalty; Turbulent Boundary Layer; Surface Roughness; Drag Penalty Estimation.
\end{abstract}

\begin{abstract}
This work discusses the efficacy of different drag penalty estimation techniques in predicting the percentage change in the average skin friction coefficient due to ship hull roughness. This includes comparing the traditional predictive method from ITTC that is currently used by the shipping industry with the recently developed estimation technique that incorporate average roughness height ka and effective slope ESs. Here the two methods are tested using a biofouling roughness case from experiments that utilize the well-known classical log-law from mean velocity profiles and the integral formulation of evolving turbulent boundary layers. The results show that the traditional estimation method from the industry can differ by approximately $15 \%$ compared to the experiment, while the more recent estimation technique differs by around $2 \%$ with respect to the experimental result. The result demonstrates that the ka and ESx based empirical technique may have potential for estimating realistic ship-hull roughness such as biofouling.
\end{abstract}

\section{Introduction}

Ship-hull roughness (both from hull mechanical defect and biofouling) is one of the primary sources of increased ship drag penalty that leads to an increase in throttling requirement. This condition translates to an increase in energy cost and emissions [1-4]. Recent reports show that even a recently cleaned ship-hull may already suffer from a substantial increase of drag compared to a hydrodynamically smooth wall $[5,6]$. Such drag penalty is caused by the combination of hull imperfection (due to repeated cleaning process such as sand or water blasting) and biofouling heterogeneity. The heterogeneity is typically caused by the patches of biofouling that remain from the previous cycle of dry-docking that are covered by docking blocks (which hold the ship-hull during the dry dock cleaning procedure). Such practice is common in the shipping industry due to the high cost of an additional dry-docking process. These conditions show the sobering and difficult issues faced by the shipping industry. Considering that for a large bulk carrier $80 \%-90 \%$ of the total drag experienced by ship could be due to skin-friction drag [7], and the costly economic and energy 
ramification of ship-hull roughness, it is imperative for hydrodynamicists to characterize such surface imperfection.

Characterizing ship-hull roughness properly is notoriously challenging. An important step in assessing surface roughness is obtaining the equivalent sand-grain roughness $k_{s}[8,9,10]$. The equivalent sand-grain roughness is a measure of the effect of wall roughness on the boundary layer flow, hence it can only be obtained by applying fluid flow over a certain rough surface. This can be done experimentally using facilities such as wind or water tunnel, channel flow, or pipe flow. By exposing a certain roughness profile to fluid flow, one could estimate the skin friction velocity $U_{\tau}$ and the coefficient of friction $C_{f}$. This process needs to be repeated over a range of Reynolds number $R e$ until $C_{f}$ becomes invariant with $R e$ (or the surface becomes what is termed "fully rough"). Determining $k_{s}$ would allow one to estimate the increase of full-scale ship-hull drag penalty due to increased hull roughness. However, obtaining $k_{s}$ experimentally is costly, particularly in terms of time and experimental apparatus (see [11] for recent reviews of various experimental techniques in estimating rough-hull drag penalty). Some may argue that computational fluid dynamics (CFD) techniques such as Direct Numerical Simulation (DNS) or Large Eddy Simulation (LES) could bypass the experimental technique. Indeed there have been numerical studies that attempt to directly simulate realistic rough surface (i.e [12]). However, in term of computational power and time required, such techniques are still costly.

Due to those issues, there have been many efforts to develop a mathematical model or empirical prediction to estimate skin friction drag that arises from turbulent boundary layer flow over rough surface. In essence these models attempt, in some way, to estimate the equivalent sand-grain roughness $k_{s}$ from directly topographical measures of the hull roughness. These models range from simple roughness height to more complex relationship such as shape parameters, density, etc [13]. For ship operators, the empirical correlation would permit an estimation of ship-hull drag penalty with a rapid turnaround, directly from a hull observation, allowing an immediate assessment of their energy expenses. Unfortunately, many of the available methods are difficult to apply in heterogeneous and highly irregular three-dimensional roughness [13], which is common in typical ship-hull roughness.

In the last few decades, the authority in ship design, the International Towing Tank Conference (ITTC) has endorsed an empirical estimation that is based on the maximum peak and minimum trough height over a $50 \mathrm{~mm}$ interval [14]. The method is often termed as Townsin estimation, and it is based on the work of [16] and [17]. It is currently the industry standard in drag penalty estimation due to hull roughness. This empirical technique however, has been the subject of various critiques. Many believe that the uses of simple roughness peak and valley measurement that form the basis of the Townsin formulae are not accurate enough in characterizing hull-roughness [18-20].

In this report, we will analyze the accuracy of Townsin estimation by comparing it with the experimental data of [10] and the recently developed empirical estimation of [22]. All three methods are tested using an identical roughness surface topography, which is a tubeworm biofouling surface. Such roughness type is commonly found in sea-going ship-hull.

\section{Surface Roughness Pattern}

The surface roughness pattern is similar to that used by [10]. It is in the form of tubeworm biofouling that comprises of Hydroides sp., Galeolaria sp. and Spirorbis sp. The biofouling was grown on an acrylic coupon and then scanned using Keyence LK-031 laser triangulation sensor attached to a two-axis computer-controlled positioning system. Fig 1 shows the resulting scanning and table 1 lists the important scanned biofouling parameters. The digital data is later scaled and replicated in the form of tiles. The replicas are manufactured via moulding and casting technique, similar to that of 
[23]. These replicas are laid inside wind tunnel and measured using hot-wire anemometer (see [10] for further experiment details)

Table 1: Biofouling surface roughness parameters from [10]

\begin{tabular}{|c|c|c|c|}
\hline \multirow{2}{*}{ Parameters } & \multicolumn{3}{|c|}{ Details } \\
\cline { 2 - 4 } & Value & Units & Equation \\
\hline$k_{a}$ & 0.094 & $\mathrm{~mm}$ & $\left|z^{\prime}\right|$ \\
\hline$k_{r m s}$ & 0.144 & $\mathrm{~mm}$ & $\sqrt{z^{\prime^{\prime 2}}}$ \\
\hline$k_{p}$ & 1.630 & $\mathrm{~mm}$ & $\max z^{\prime}-\min z^{\prime}$ \\
\hline$k_{s k}$ & 2.963 & - & $\overline{z^{\prime 3} / k_{r m s}^{3}}$ \\
\hline$k_{k u}$ & 14.180 & - & $\overline{z^{\prime 4} / k_{r m s}^{4}}$ \\
\hline$E S_{x}$ & 0.134 & - & $\overline{\left|d z^{\prime} / d x\right|}$ \\
\hline
\end{tabular}

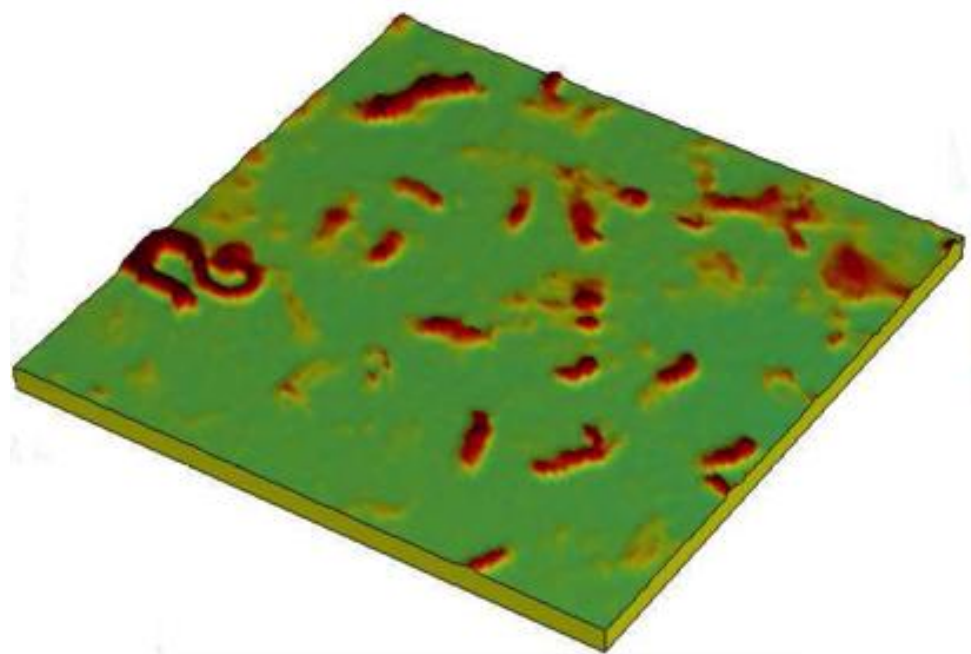

Figure 1: Tubeworm biofouling from [10]

\section{Boundary Layer Over Roughness Experiment}

To assess the rough-wall turbulent boundary layer, [10] measured the velocity profile above the biofouling pattern at several Reynolds numbers. The skin friction velocities $U_{\tau}$ are estimated via the well-established modified log-law [24-26], which can be expressed as

$$
\frac{U}{U_{\tau}}=\overbrace{\frac{1}{\kappa} \ln z^{+}+A}-\Delta U^{+}+\overbrace{\frac{\Pi}{\kappa} W\left(\frac{z}{\delta}\right)}
$$

Here $z$ is wall normal position, $U$ is velocity, $\kappa$ and $A$ are $\log$ law constant with value 0.4 and 4.17 respectively. $W$ is wake function, and $\Pi$ is wake strength with value 0.65 . The + superscript indicates viscous scaling where $z^{+}=z U_{\tau} / v$ and $v$ is kinematic viscosity. 
$\Delta U^{+}$is Hama Roughness function [27] and in the fully rough limit can be defined as:

$$
\Delta U^{+}=\frac{1}{\kappa} \ln k_{s}^{+}+A-B
$$

Here $B$ is typically 8.5, taken from [8]. The Hama roughness function represents the increase of skin friction velocity in mean velocity profile. This condition is indicated by the vertical downward shifts of the mean velocity profile with Reynolds number when it is compared to the canonical smooth wall profile.

Fig 2 shows the mean velocity profile from [10]. The solid grey square shows the canonical smooth walled boundary layer flow, while the rest are flow over the rough wall with increasing Reynolds number. The plot clearly shows the vertical downward shift (Hama roughness function) of the mean velocity profile with $R e$. Fig 3 shows the velocity profile shift as a function of viscous scaled sand grain equivalent roughness. By fitting these data to the equation for fully rough behavior (equation 2 - given by the dashed line on figure 3) It is possible to determine the equivalent sand-grain roughness of the tubeworm surface. In this case the $k_{s}$ of the tube worm is found to be $0.325 \mathrm{~mm}$ (which can be compared to topographical surface measures from table I).

Here $B$ is typically 8.5 , taken from [8]. The Hama roughness function represents the increase of skin friction velocity in mean velocity profile. This condition is indicated by the vertical dow nward shifts of the mean velocity profile with Reynolds number when it is compared to the canonical smooth wall profile.

Fig 2 shows the mean velocity profile from [10]. The solid grey square shows the canonical smooth walled boundary layer flow, while the rest are flow over the rough wall with increasing Reynolds number. The plot clearly shows the vertical downward shift (Hama roughness function) of the mean velocity profile with Re. Fig 3 shows the velocity profile shift as a function of viscous scaled sand grain equivalent roughness. By fitting these data to the equation for fully rough behavior (equation 2 - given by the dashed line on figure 3 ) It is possible to determine the equivalent sand-grain roughness of the tubeworm surface. In this case the ks of the tube worm is found to be $0.325 \mathrm{~mm}$ (which can be compared to topographical surface measures from table I).

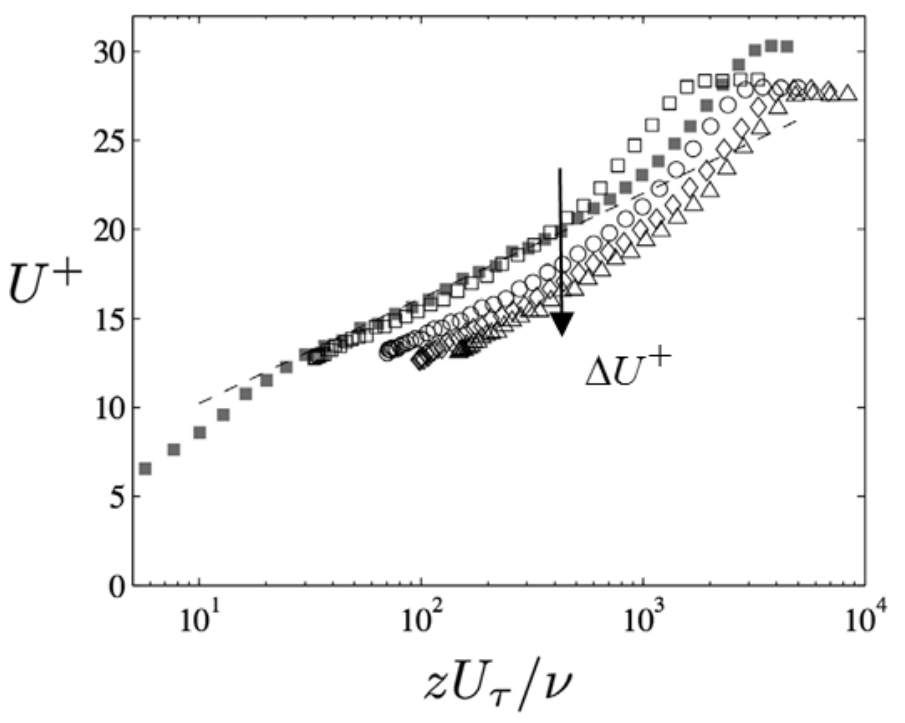

Figure 2: Mean velocity profile from [10] 
The resulting $k_{s}$ value can be used to estimate the drag-penalty of full scale ship by implementing mean momentum integral equation [30, 31]. The integral equations are solved numerically, allowing a simple calculation for various type of roughness along flat-plate. For this report, we use ship data from [3], a US Navy Oliver Hazard Perry class frigate (FFG-7) with cruise speed of $7.7 \mathrm{~m} / \mathrm{s}$ and length of $124.4 \mathrm{~m}$.

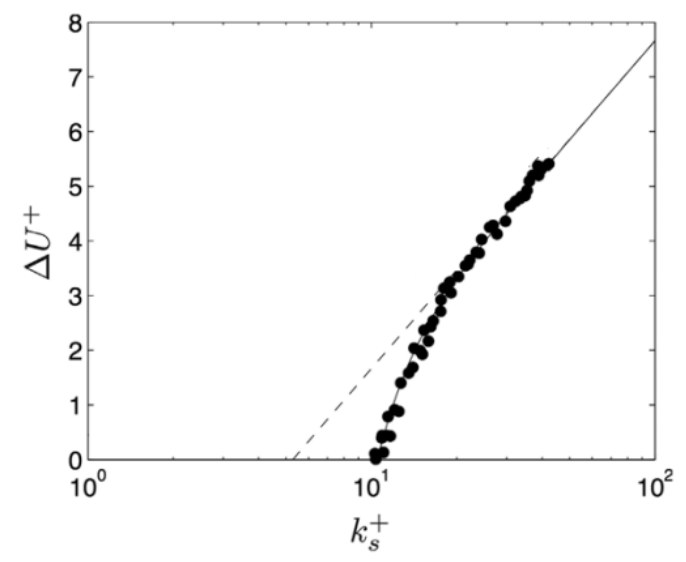

Figure 3. Velocity profile shift as function of viscous scaled sand grain equivalent roughness

Figure 4 shows the average skin friction coefficient against $\operatorname{Re}_{\mathrm{x}}$ Reynolds number that is based on streamwise distance. Here the blue line is for the tubeworm rough surface and black is the hydrodynamically smooth surface. The vertical black line shows the Reynolds number at the FFG7cruise speed. At this $R e_{x}$, the average skin friction $C_{f}$ for a smooth wall is $1.484 \times 10-3$ (at the intersection of the black dashed line and solid black line). For the tubeworm surface the average skin friction $C_{f}$ is $2.165 \times 10-3$ (at the cross between black dashed line and blue line). Hence the percentage change in $C_{f}$, or $\Delta C_{f}$ is around $46 \%$.

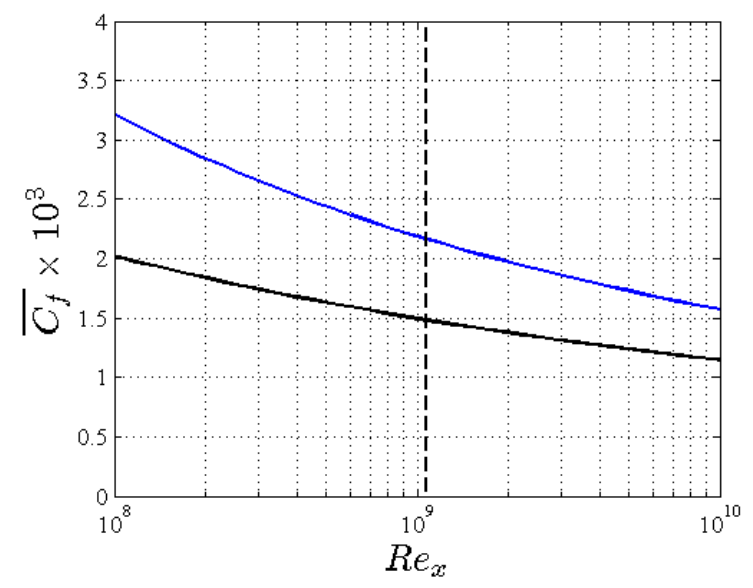

Fig 4. Average skin friction coefficient versus Reynolds number for the smooth surface (black line) and biofouling rough surface (blue line) from [10]. The vertical dashed black line is the Reynolds number of FFG-7 at cruise speed from [3].

Although estimating drag penalty via experiment is already well-established, it is costly, both in term of facility and time. For illustration, a standard wall-normal direction mean velocity profile measurement using hot-wire Anemometer or Laser Doppler Anemometer will take 3-5 hours to perform. Furthermore, as previously mentioned, in order to obtain sufficient Hama-Roughness 
function for estimating $k_{s}$, one would need to perform many measurements at different Reynolds number. This is in addition to the cost of scanning, scaling and replicating the rough surface $\left(5 \mathrm{~m}^{2}\right.$ of the tubeworm surface was manufactured for the study of [10])

\section{Townsin Drag Penalty Estimation}

Although estimating drag penalty via experiment is already well-established, it is costly, both in term of facility and To bypass the expensive experiment method, it is desirable to have an empirical estimation that can predict the drag penalty caused by a rough surface. This is particularly important for the shipping industry. Since 1970's there has been plenty of efforts by the authority, International Towing Tank Conference (ITTC), to come up with an accurate empirical prediction. Currently, the accepted industry standard estimation method is the Towsin formulae [15]:

$$
\Delta C_{f}=\frac{44}{1000}\left[\left(\frac{A H R}{L}\right)^{1 / 3}-\left(10 R e_{x}\right)^{-1 / 3}\right]+\frac{0.125}{1000}
$$

Here AHR is the average of a number of hull roughness measurements of Rt50, which is the maximum peak to minimum valley of roughness height over $50 \mathrm{~mm}$ length recorded by a hull roughness sensor, and $\mathrm{L}$ is ship hull length.

The issue with equation 3 is the use of maximum peak and trough height as the sole roughness characteristics. Many laboratory and numerical works have shown that there is a wide range of surface roughness properties that can contribute to the dynamic of the flow. These include solidity, average roughness height, effective slope, etc [13, 21, 22, 26, 32]. This limitation can be seen from applying the roughness sample of [10] onto the Townsin estimation. Here the AHR of the biofouling sample is $0.607 \mathrm{~mm}$ and we apply it on the same FFG-7 ship of [3] at cruise speed. Using these parameters, equation (3) would yield a percentage change in Cf: $30 \%$, which is around $16 \%$ lower than that of the experiment by [10].

\section{Average Roughness Height and Effective Slope Based Drag-Penalty Empirical Estimation}

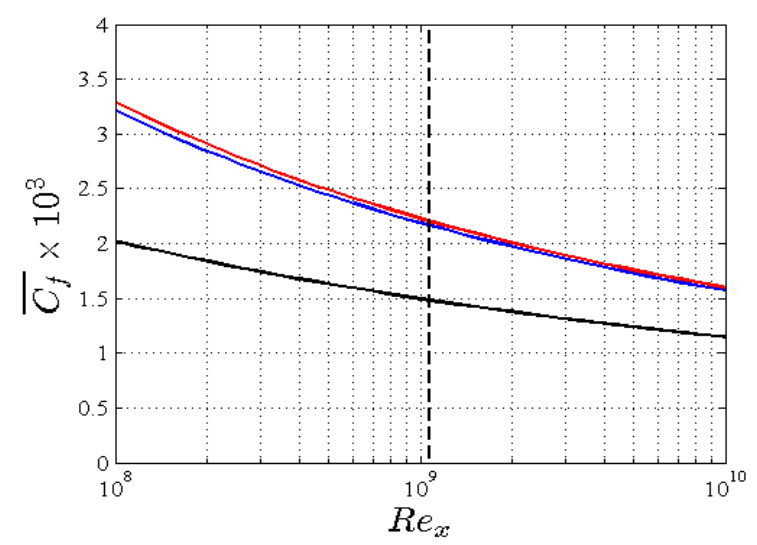

Figure 5: Average skin friction coefficient versus Reynolds number for the smooth surface (black line), biofouling rough surface estimation from [10] experiment (blue line), biofouling rough surface estimation from [21] (red line). The vertical dashed black line is the Reynolds number of FFG-7 at cruise speed from [3]. 
Recent report by [21] shows that in order to properly estimate the increase of drag penalty due to surface roughness, one would need a minimum of two roughness parameters. Here they propose that average roughness height and effective slope are sufficient parameters, that can be easily obtained from surface scanning or imprint. The empirical estimation proposed by [21] is in the form of:

$$
\Delta U^{+}=\frac{1}{\kappa} \ln k a^{+}+\beta \log E S x+\gamma
$$

Here $^{\beta}$ and ${ }^{\gamma}$ are constants with value 1.12 and 1.47 respectively, and ESs is effective slope. This empirical estimation can be combined with the integral formulation of evolving turbulent boundary layers from [10] to estimate the drag penalty of full scale ship.

Fig 5 shows the comparison of increased ship drag penalty between the laboratory experiment by [10] (blue line) and empirical estimation by [21] (red line), using the same biofouling roughness. At similar Reynolds number of FFG-7 cruise speed, the increase of drag penalty estimated via this new empirical method is around $48 \%$, which is only $2 \%$ difference from the experiment result.

Table 2: Biofouling surface roughness parameters from [10]

\begin{tabular}{|l|c|c|c|}
\hline \multirow{2}{*}{\multicolumn{1}{|c|}{ Methods }} & \multicolumn{3}{|c|}{ Details } \\
\cline { 2 - 4 } & Rex & AHR $(\mathrm{mm})$ & $\Delta C_{f}(\%)$ \\
\hline Experiment based estimation & $1.07 \times 109$ & 0.607 & 46 \\
\hline Townsin estimation & $1.07 \times 109$ & 0.607 & 30 \\
\hline Ka and ESx based estimation & $1.07 \times 109$ & 0.607 & 48 \\
\hline
\end{tabular}

\section{Conclusions}

A comparison between an industry standard drag penalty estimation method (Townsin estimation) and a more recent estimation technique that is based on roughness height and effective slope is discussed. The result shows that the Townsin estimation is unable to match the laboratory result. The result differs by $15 \%$. On the other hand, the new empirical estimation only has $2 \%$ differences with the laboratory result (see table 2). Note that the new empirical approximation is still under development and only serves as a preliminary estimation. Further experimental studies and numerical simulations using different surface patterns are needed to confirm the efficacy of the new estimation technique. However, recent results do seem to suggest that in relating topography to equivalent sandgrain roughness, as a bare minimum some measure of effective slope or solidity will also need to be considered in addition to a roughness height measure (such as Rt50 or $k_{a}$ ).

\section{Acknowledgements}

The authors would like to thank the Australian Research Council, the Newton Fund, and the Australia Indonesia Center for support of this work.

\section{References}

[1] Townsin R.L., "The ship hull fouling penalty”. Biofouling, vol. 19, pp. 9-15, 2003.

[2] Schultz, M. P., "Frictional resistance of antifouling coating systems". J. Fluids Eng, vol. 126, no. 6, pp. 1039-1047, 2004. 
[3] Schultz, M. P., "Effects of coating roughness and biofouling on ship resistance and powering”. Biofouling, vol. 23, no. 5-6, pp. 331-341, 2007

[4] V. Erying, I. Isaksen, T. Bemsten, W. J. Collins, J. J, Corbett, O. Endersen, R. G. Grainger, J. Moldavon, H. Schlager, D. S. Stevenson, "Transport impacts on atmosphere and climate: Shipping", Atmos. Environ, vol.44 No.37, pp.47354771, 2010

[5] B. Nugroho, R. Baidya, M. N. Nurrohman, A. K. Yusim, F. A. Prasetyo, M. Yusuf, I. K. Suastika, I. K. A. P. Utama, J. P. Monty, N. Hutchins, B. Ganapathisubramani, "In-situ turbulent boundary layer measurements over freshly cleaned ship-hull under steady cruising”. Royal Institution of Naval Architects (RINA) Conference, International Conference on Ship and Offshore Technology (ICSOT). Jakarta, Indonesia, 2017

[6] I. K. A. P. Utama, B. Nugroho, C. Chin, M. L. Hakim, F. A. Prasetyo, M. Yusuf, I. K. Suastika, J. P. Monty, N. Hutchins, B. Ganapathisubramani, "A study of skin friction drag from realistic roughness of a freshly cleaned and painted ship hull". International Symposium on Marine Engineering (ISME). Tokyo, Japan, 2017

[7] Lackenby, H., "Resistance of ships, with special reference to skin friction and hull surface condition". Proc Inst Mech Eng, vol. 176, pp. 981 - 1014, 1962

[8] Nikuradse J., "Gesetzmassigkeiten der turbulenten stromung in glatten rohren”. Forsch Auf Dem Gebiet des Ingenieurwesens, vol. 3, pp. 1-36, 1932

[9] Granville, P.S., "The frictional resistance and turbulent boundary layer of rough surfaces". J. Ship. Res, vol. 2, pp. 52-74, 1958

[10] Monty, J.P., Dogan, E., Hanson, R., Scardion, A.J., Ganapathisubramani, G., Hutchins, N., "An assessment of the ship drag penalty arising from light calcareous tubeworm fouling. Biofouling. Vol. 32, no.4, pp. 451-464, 2016.

[11] Lindholdt, A., Dam-Johansen, K., Olsen, S. M., Yebra, D. M., Kiil, S. "Effects of biofouling development on drag forces of hull coatings for ocean-going ships: a review”. Journal of Coatings Technology and Research, vol. 12, pp. 415-444, 2015

[12] Busse, A., Lützner, M., Sandham, N.D., "Direct numerical simulation of turbulent flow over a rough surface based on a surface scan". Comput Fluids, vol. 116, pp. 129-147, 2015

[13] Flack, K.A., Schultz, M.P., "Review of Hydraulic Roughness Scales in the Fully Rough Regime”. ASME. J. Fluids Eng, vol.132, no. 4, 041203-041203-10, 2010

[14] ITTC,. "The powering and performance committee final report and recommendation". International Towing Tank Conference 19th. Madrid, Spain, 1990

[15] ITTC,." Recommended Procedures and Guidelines". 7.5-02-02-03, 2017

[16] Townsin, R.L., Byrne, D., Svensen, T.E., Milne, A., "Estimating the technical and economic penalties of hull and propeller roughness”. Trans. Soc.Nav. Archit. Mar. Engrs, vol. 89, no. 295-318, 1981

[17] Townsin RL. The ship hull fouling penalty. Biofouling, vol. 19, pp. 9-15, 2003

[18] Grigson, C., "The full scale viscous drag of actual ship surfaces and the effect of quality roughness on predicted power". J. Ship. Res, vol. 31, no. 3, pp. 189-206, 1987

[19] Grigson, C., "Drag losses of new ships caused by hull finish”. J. Ship. Res. Vol. 36, no.2, pp. 182-196, 1992

[20] Howell, D., Behrends, B., "A review of surface roughness in antifouling coatings illustrating the importance of cut off length". Biofouling. vol. 22, no. 6, pp. 401-410, 2006

[21] Chan, L., MacDonald, M., Chung, D., Hutchins, N., Ooi, A., "A systematic investigation of roughness height and wavelength in turbulent pipe flow in the transitionally rough regime”. J. Fluid Mech, vol.771, pp. 743-777, 2015

[22] Hutchins N., Monty J. P., Nugroho, B., Ganapathisubramani, B., Utama, I. K. A. P. "Turbulent boundary layers developing over rough surfaces: from the laboratory to full-scale systems". Plenery speaker paper. 20th Australasian Fluid Mechanics Conference (AFMC). Perth, Australia, 2016

[23] Nugroho B., Hutchins N., Monty J.P. "Large-scale spanwise periodicity in a turbulent boundary layer induced by highly ordered and directional surface roughness. Int J Heat Fluid Fl, vol.41, pp. 90-102, 2013

[24] Clauser, F.H., Turbulent boundary layers in adverse pressure gradients. J. Aeronaut Sci, vol. 21, pp. 91-108, 1954.

[25] Perry, A.E., Schofield, W.H., Joubert, P.N., “Rough wall turbulent boundary layers”. J. Fluid Mech vol.37, pp. 383413, 1969

[26] Jim'enez, J., “Turbulent flows over rough walls”. Annu. Rev. Fluid Mech, vol. 36, pp. 173-196, 2004

[27] Hama, F.R., Boundary-layer characteristics for smooth and rough surfaces. Trans. Soc. Nav. Archit. Mar. Engrs, vol. 62, pp. 333-358, 1954

[28] Townsend, A.A., “The structure of turbulent shear flow”, 2nd ed. Cambridge University Press, 1976

[29] Flack, K.A., Schultz, M.P., Shapiro, T.A.,. "Experimental support for townsend's reynolds number similarity hypothesis on rough wall". Phys. Fluids, vol.17, no. 035102, 2005

[30] Monty, J.P., Allen, J.J., Lien, K., Chong, M.S., "Modification of the largescale features of high reynolds number wall turbulence by passive surface obtrusions". Exp. Fluids, vol. 51, pp. 1755-1763, 2011.

[31] Pullin, D. I., Hutchins, N, and Chung, D., Turbulent flow over a long flat plate with uniform roughness. Phys. Rev. Fluids 2, 082601(R)

[32]MacDonald. M, Chan. L, Chung. D, Hutchins. N, and Ooi. A. Turbulent flow over transitionally rough surfaces with varying roughness densities. J. Fluid Mech., vol. 804, pp. 130 -161 